\title{
Biografia coletiva, engajamento e memória: A miséria do mundo
}

\author{
Miguel Ângelo Montagner
}

Introdução

$\mathrm{O}$ interesse inicial neste artigo é discutir a mudança metodológica nos trabalhos de Pierre Bourdieu, notadamente em $A$ miséria do mundo, sobretudo no período de declarado e progressivo engajamento no cenário público francês e mundial, quando o autor passou a ocupar sistematicamente os espaços da mídia. Ao mesmo tempo, esperamos contribuir com uma proposta de análise de dados qualitativos obtidos por meio de histórias de vida ou biografias, baseada na discussão dos métodos do "construtivismo genético" daquele autor, em paralelo com outras concepções de tratamento desse tipo de abordagem.

$\mathrm{Na}$ primeira parte deste trabalho, retomamos algumas grandes linhas de análise do papel do intelectual nas sociedades modernas para, em seguida, mostrar como as posturas daí decorrentes refletem-se na própria "teoria em ato" das pesquisas. Na sequência, discutimos as possibilidades de um método que promova e valorize tanto o material advindo das visóes de mundo dos entrevistados como as exigências de rigor científico do mundo acadêmico, assim reabrindo e incorporando as concepçôes de Halbwachs sobre a "memória coletiva". 


\section{O modelo de A miséria do mundo}

Podemos considerar que Bourdieu sempre trabalhou com uma perspectiva científica na qual a ideia de biografia individual jogou um papel secundário e, em si mesma, nunca foi um material sociológico nobre. Por isso abre seu livro Esquisse pour une auto-analyse (cf. Bourdieu, 2004) com a epígrafe "Esta não é uma autobiografia". Mais que uma metáfora do célebre quadro La trahison des images do pintor surrealista René Magritte, no qual ele representa uma foto de um cachimbo acompanhada da frase "isto não é um cachimbo", o que Bourdieu apontava era que a objetivação de partes de sua biografia não era uma autobiografia, mas uma representação de outra coisa, no caso, o campo científico em que sua biografia estivera imersa até então. Como representação, depende de toda uma técnica de observação, recolhimento, codificação, análise e interpretação que nada tem de arbitrária ou somente subjetiva e pessoal.

Quando condenou a "ilusão biográfica", condenou de fato a posição metodológica dos pesquisadores preocupados em traçar panoramas individuais de sujeitos históricos, portadores da capacidade de instaurar por si mesmos um projeto criador excepcional e extrassociedade: é o que ataca intensamente no projeto pessoal de Sartre (cf. Bourdieu, 1986).

No entanto, como mostram seus últimos trabalhos, a partir de sua aposta na posição de um intelectual que atua nos movimentos sociais e por meio de suas intervenções públicas, Bourdieu assumiu novos rumos e investiu na possibilidade de fazer do científico uma base social do intelectual atuante e, para usarmos a palavra tabu, engajado. A discussão sobre o papel dos intelectuais sempre é candente, mas o que nos interessa, sobretudo nesse caso, é que sua inflexão política levou a uma mudança teórica em seus últimos trabalhos, mesmo que essa nova abordagem tenha sofrido uma interrupção com sua morte.

Vale lembrar que o vocábulo engajado é de origem latina, um galicismo que significa recrutar e colocar alguém a serviço de outrem; em situação de responsabilidade e implicação. Para Foucault, esse papel de intelectual engajado passou por uma forte mudança a partir da Segunda Guerra Mundial, e a prática de pensar o universal, as grandes temáticas, os grandes problemas e as questóes humanas mais prementes deixou de ser atributo de "uma consciência de todos", de "uma lúcida e individual figura da universalidade". Aqui, o grande exemplo francês fora Sartre. Uma nova relação entre teoria e prática, entre conhecimento e engajamento, nasceria com o 
intelectual concreto, "específico", ligado a conflitos que se desenrolam à sua frente e em seu domínio de conhecimento, em poucos e definidos setores, nos quais sua vida e seu trabalho se mesclariam de maneira inderrogável (cf. Foucault, 1988, p. 9).

\section{Os intelectuais e a cultura}

Essa passagem de intelectual universal a específico remete, em muitos aspectos, àquela já extensamente teorizada por Gramsci em Os intelectuais e a organização da cultura (1978b), livro em que discute não somente suas posições acerca dos intelectuais, sobretudo no que tange à sua definição e formação, mas também o seu caráter como organizadores da sociedade.

A preocupação em repensar a relação entre a teoria e a prática, ou o engajamento político, surgiu inevitavelmente na obra desse autor após o fracasso do movimento operário italiano no qual participara intensamente. Gramsci procurou pensar as instâncias simbólicas da dominação social e percebeu, com grande lucidez, que as chaves do entendimento da inércia e do conservadorismo das massas proletárias estavam ligadas à reprodução dessa dominação dentro do senso comum, em resumo, à cultura social.

$\mathrm{Na}$ sua concepção teórica, é central o conceito de "bloco histórico", que representa a totalidade concreta da sociedade por meio das relações dialéticas entre estrutura cultural e estruturas econômicas. Nela emerge uma valorização das superestruturas como fator relevante na interpretação do mundo, pois a autoconsciência de uma classe estaria ligada à construção, a partir da práxis, de uma concepção teórica advinda dos intelectuais.

Por esses motivos, entre outros, Gramsci propôs em seus trabalhos uma valorização das experiências tradicionais tanto da população, e especialmente dos operários, como dos pensadores que surgem dos movimentos dialéticos entre a práxis humana e o pensamento sobre essa prática. No primeiro caso, temos o conceito de "bom senso", e, no segundo, o de "intelectual orgânico”.

A existência embrionária da intelectualidade em todo ser humano, embutida na constatação de que toda atividade humana gera algum tipo de conhecimento, significa uma valorização humanista do homem e o coloca como agente central de sua própria história e de sua sociedade. Na realidade, nem todos os indivíduos atuam como intelectuais e nem todos estão fadados a atingir um elevado grau de consciência, ou seja, transitar de uma “consciência em si” para uma "consciência para si”. 
Esse processo de formação dos intelectuais orgânicos é histórico e eles não constituem uma classe autônoma e independente, nem homogênea e transparente. Para Gramsci, rigorosamente nada distingue um homem como intelectual, a não ser, como diria Fernando Pessoa, o fato de estar doente dos olhos.

As novas categorias históricas de intelectuais que surgiram a partir da práxis humana, e que seriam assim revolucionários, teriam encontrado outras já encravadas na sociedade e que mantinham uma continuidade de atuação no corpo social; categorias "tradicionais" e de certa forma atemporais por sua continuidade histórica. Esses intelectuais "tradicionais" acabam por se interpretar como independentes dentro da sociedade.

Dessa forma, o que determinaria o intelectual seria sua inserção nas infraestruturas sociais, pois cada estrutura produtiva engendra suas próprias categorias de intelectuais orgânicos ligados a setores fundamentais de seu funcionamento. Dessas premissas gramscianas, infere-se que os intelectuais não formam uma classe em si, mas exercem uma função em relação a outras classes sociais, sobretudo servindo aos grupos dominantes que controlam esse mundo produtivo.

Determinadas condições materiais e relações sociais de um grupo se traduzem em uma determinada visão de mundo que acaba apropriada pelos indivíduos, mas somente alguns atingem completamente a plena consciência de sua classe. Aqui encontramos eco no conceito de habitus de Bourdieu, se o considerarmos como um conjunto incorporado de disposições engendrado pela origem social e a socialização primária.

Essa conscientização particularizada só pode ser explicada se levarmos em conta o papel da subjetividade pessoal, de uma desviância idiossincrática em relação ao grupo, pois somente uma parcela tornar-se-ia intelectuais orgânicos. Isso lembra em muito a ideia em Bourdieu de um habitus individual em desacordo com o "habitus de classe", o que gera a possibilidade de inovações na sociedade.

Em seu filme Viver, de 1952, Akira Kurosawa mostra limpidamente esse processo de ruptura entre um trabalho mecânico e uma tomada de consciência social pela descrição da trajetória de um burocrata, após a revelação de sua morte próxima. Sua personagem elabora e executa o plano de um jardim público, uma necessidade não atendida pelas instâncias burocráticas da qual faz parte, lutando pela realização desse desejo coletivo: atua assim de forma específica e relacionada com seu meio social.

Essa passagem de um tipo de consciência a outro aconteceria principalmente no campo político e das ideologias, isto é, no campo da cultura. A 
instituição por excelência que atua na sociedade objetivando a formação dos intelectuais é o sistema educacional. Isso é comprovado pela sua grande extensão e propagação nas sociedades capitalistas, nas quais é necessário ao mundo produtivo e ligado a cada ramo industrial de forma especializada. Nesse sentido, sua teoria enfatiza a escola como um importante ponto de apoio do surgimento de intelectuais dirigentes, da mesma forma como propusera Durkheim em seus trabalhos, depois retomados por Pierre Bourdieu, um grande teórico da socialização pelas instituiçōes reprodutoras do mundo escolar.

Assim, só o capital dá acesso ao conhecimento, inclusive sobre ele mesmo. Conforme Gramsci, "a tendência democrática não está em qualificar um operário manual, mas em que a sociedade coloque cada cidadão em condições, mesmo que idealmente, de se tornar um governante" (Gramsci, 1978b, p. 137). Se nas sociedades ocidentais modernas o sistema universitário tornou-se o espaço preferencial de formação dos intelectuais, isso ocorreu por conta de uma profissionalização crescente de seu papel nas sociedades.

A configuração das sociedades posterior às teorias de Gramsci, sobretudo nos países europeus, parece comprovar suas ideias. $\mathrm{O}$ peso cada vez mais acentuado do mundo cultural, atestado pelo desenvolvimento extraordinário dos meios de comunicação de massa e da indústria cultural, parece atuar como elemento fundamental na alienação, no controle e na submissão das classes subalternas às classes dominantes (cf. Ortiz, 1989, 2002).

No mundo contemporâneo, a indústria cultural assume proporções inauditas e torna-se um centro irradiador de ideologias muito mais potente que os discursos avulsos dos próprios intelectuais, pois atua de maneira avassaladora nas sociedades. Estando enraizada tanto no mundo econômico como no campo das superestruturas, a indústria cultural representa a síntese perfeita entre ambos.

Assim, grosso modo, os intelectuais partilham e participam do aparato organizador e coercitivo representado pelo Estado ou sociedade política. Para Gramsci (1978a), são instrumentos de propaganda da ideologia da dominação cuja disseminação leva ao consenso dentro da sociedade civil e exercem o governo político a soldo do grupo hegemônico, reprimindo as ideologias e as ações desviantes da política do Estado. Ou, então, são os responsáveis pela "elaboração conceitual e filosófica" da relação entre a práxis e a teoria; em suma, da "autoconsciência crítica" das classes revolucionárias. Desse modo, o intelectual revolucionário continua uma figura nada hegemônica nas sociedades modernas. 


\section{Mannheim}

No mesmo período, Karl Mannheim propunha uma visão em alguns pontos parecida com a gramsciana quanto aos tipos de intelectuais, mas suas conclusões são diametralmente diferentes. Os que seriam os intelectuais tradicionais em Gramsci, conservadores e a-históricos, na concepção de Mannheim seriam os verdadeiros intelectuais, libertos de qualquer compromisso utópico (de classe) e de qualquer tipo de "organicidade". Mannheim buscou entender as raízes históricas e sociais do que se define como intelectual. Ele estabeleceu uma linha de estudos em torno da prática e do tipo de origem daqueles que se propõem a pensar as sociedades e a relação dos homens com elas. Para o autor, uma ideologia era uma interpretação sobre um momento histórico que resulta não de experiências concretas e reais, mas sim de um tipo de conhecimento idealizado e desligado da realidade que visa mascarar a situação de fato e que age restritivamente sobre o indivíduo. Tanto a ideologia como a utopia são uma espécie de falsa consciência, mas a primeira é ligada ao passado e exerce a função de conservação social, enquanto a segunda olha o futuro e exerce uma influência revolucionária:

Limitando o sentido do termo utopia a esse tipo de orientação que vai além da realidade e que, ao mesmo tempo, libera as amarras da ordem existente, nós estabelecemos uma distinção entre os estados de espírito utópicos e ideológicos. Podemos nos orientar para objetos que são estranhos à realidade e que ultrapassam a existência real, e não obstante permanecer ainda atuantes na realização e manutenção do estado atual das coisas. [...] Uma tal orientação em desacordo não se torna utópica a não ser que tendesse a romper as ligações da ordem existente (Mannheim, 1976).

Para Mannheim, em todas as formas societárias sempre existiu "uma camada mais orientada para o que chamamos de domínio do espírito", e nas sociedades modernas os intelectuais atingiram um ponto do processo histórico no qual suas raízes e ligações com as camadas sociais de origem estão em vias de desaparecimento, pois em sua análise a utopia foi banida da política, e os intelectuais, até então encarregados das ideias utópicas, foram liberados dessa função. Essas pessoas, um pequeno grupo, que "se interessam por outra coisa que não o sucesso no plano da competição, que visa substituir o estado atual”, estarão "condenadas" à liberdade: 
Os intelectuais serão, eles também, liberados das ligações sociais tão logo a camada mais oprimida da sociedade venha a dirigi-la. Somente os intelectuais que não têm nenhuma ligação social serão, mais que hoje em dia, recrutados, em maior proporção, em todas as camadas sociais, e não mais unicamente nas mais privilegiadas. Esse setor dos intelectuais, que se separa mais e mais do resto da sociedade e que é deixado as suas expensas, se encontra colocado, sob outro ângulo, na presença da situação que viemos de caracterizar: situação total tendendo a desaparição completa da tensão social (Idem, p. 112).

A proposta de intelectuais sem raízes, desligados e desobrigados socialmente foi duramente criticada, e na realidade prática os espaços em que existe a autonomia absoluta nas escolhas dos percursos das pesquisas e da atuação intelectual são cada vez mais perigosamente exíguos. A autonomia da ciência torna-se progressivamente relativa.

Dessa digressão, podemos concluir que a teoria gramsciana de um intelectual orgânico guarda grandes afinidades com a concepção de Foucault do intelectual específico: ligado a setores determinados da sociedade, portador de um conhecimento aprofundado sobre um conjunto regional de micropoderes e capaz, assim, de uma atuação local. E ambas as propostas se opōem fortemente ao que Mannheim vislumbrava como o panorama futuro dos intelectuais, sem raízes.

\section{A posição do intelectual em Bourdieu}

Em geral, podemos destacar duas vertentes quanto ao papel do intelectual em Bourdieu: a primeira, a de um agente universal da razão, promotor e criador da verdade científica e do conhecimento aprofundado da sociedade; e outra, a de um agente que legitima ações políticas e reivindicações sociais por meio do seu capital científico, que lhe promove um capital simbólico transferível desse campo ao campo social.

A rigor, nunca houve na obra de Bourdieu uma distinção específica entre saber neutro ou engajado, mas sim quanto às condiçôes de produção de um saber verdadeiramente científico, que é a expressão de uma autonomia relativa de determinado campo de produção cultural, mais ou menos subordinado aos campos dominantes da sociedade. Pode-se mesmo afirmar o contrário, que "o engajamento do saber de Bourdieu está epistemologicamente inscrito em sua obra" (Bensaïd e Corcuff, 1998). 
No entanto, as diferenças de ênfase entre os dois polos acarretam, além da discussão quanto à atuação política de Bourdieu, uma mudança no perfil epistemológico de seus trabalhos. A utilização do capital científico como argumento de base para uma intervenção, cujo grande exemplo é o livro $A$ miséria do mundo, foi realmente uma aposta polêmica, pois representa também um investimento político por meio do qual a questão do engajamento intelectual foi trazida para a ordem do dia. Esse livro foi o resultado de duas apostas simultâneas: uma intervenção propriamente política e, ao mesmo tempo, uma proposição epistemológica. A fórmula que pode resumir isso é "politizar a individualidade" (Pinto, 2006).

Politicamente, Bourdieu visava tornar pública a questão das desigualdades sociais na França. A partir dos anos de 1980, a percepção social geral, alimentada por uma série de sintomas cotidianos, era de que as disparidades sociais aumentavam e a pobreza se disseminava. Esse ambiente gerou longos debates e uma série de estudos procurou delinear esse processo. Paugam (2005) afirma que essa percepção generalizada deve-se ao fato de a França estar passando de um quadro de pauvreté marginale a um quadro de pauvreté disqualifiante. No primeiro quadro, de pobreza marginal, a pobreza ainda é combatida e é motivo de debate em torno do tema da desigualdade e da divisão das riquezas; nele existe um número pequeno de pessoas com o status social de pobres, que, nessa situação, são tratados como casos sociais. No segundo, de pobreza desqualificante, há uma tomada de consciência coletiva do surgimento de uma nova pobreza ou da ideia de exclusão, com uma grande disparidade de situações e de status social, o que leva a uma dificuldade de tornar inteligível o fenômeno.

A maneira de denunciar, politicamente, esse estado de coisas, por meio dos instrumentos científicos à disposição, encontrada por Bourdieu e o grupo de pesquisadores ao seu redor, foi trazer as pequenas misérias cotidianas para a ordem do dia no livro $A$ miséria do mundo: de um lado, as "misérias de posição" - causadas por uma queda de estatuto social -; de outro, as misérias dos "excluídos do interior" - aqueles que ocupam uma posição dominada e subalterna dentro do mundo social e sofrem a precariedade de sua situação, assim como a exclusão pela imigração e pela mudança geracional -, os estrangeiros em vias de aculturação e os filhos de imigrantes aculturados embora não integrados na nova sociedade de seus pais.

Além disso, esse movimento representou uma aposta teórica: encontrar uma perspectiva de estudo de caso minuciosa, aplicar ao individual uma teoria global e complexa como o "construtivismo genético" de Bourdieu, 
que, em geral, busca explicações estruturais e portanto foi frequentemente questionado e acusado de incapaz de se ater aos problemas menores e cotidianos dos agentes sociais. Essa aposta epistemológica representa uma nova maneira de abordar a práxis social, incorporando com mais profundidade as experiências cotidianas das pessoas. Veremos com mais detalhes essa aposta, delineando as opçôes feitas por Bourdieu.

Uso político da ciência ou redefinição do objeto

Essa proposta esboçada por Bourdieu seguramente levanta problemas teóricos e metodológicos que não escaparam aos olhos atentos dos pares ou dos ímpares. Um conjunto de críticas foi endereçado, pelos últimos, aos métodos utilizados por Bourdieu em seu livro, como as de Nonna Mayer (1995).

Regra geral, a autora aponta como problemáticas algumas questōes, inicialmente em relação ao objeto: conforme os cânones sociológicos pouco seguidos e muito comentados, deve-se realizar uma definição clara do objeto de estudo, rompendo com as pré-noções e o senso comum - a noção de "miséria" não teria sido suficientemente analisada, prestando-se a confusões com termos como sofrimento, dor e infelicidade (cf. Idem, p. 358).

Em seguida, a escolha da amostra. Das 182 entrevistas realizadas, para Mayer sem uma explicitação dos critérios de seleção e de sua representatividade no sentido não estatístico, foram publicadas somente 62 , com suas análises, ainda sem maiores esclarecimentos.

Outra crítica: a estruturação da entrevista não seria de fácil classificação em nenhum item das tipologias normais, que vão desde o questionário estruturado à entrevista não diretiva, pois Bourdieu afirma em seu postscriptum a necessidade imperiosa de evitar toda e qualquer "violência simbólica" derivada da dessimetria entre entrevistador e entrevistado (cf. Bourdieu, 2003, p. 695). Essa característica induziu Bourdieu a utilizar entrevistadores autóctones, ou seja, que viviam na mesma situação e espaço social dos entrevistados; por outro lado, essa tática causaria uma dificuldade de objetivação e de distanciamento entre interlocutores iguais, e a entrevista correria o risco de não ser bem-sucedida.

Nas entrevistas que realizou pessoalmente, o modus operandi de Bourdieu foi caracterizado pela autora como invasivo, pois seu "engajamento foi muito longe" na condução das entrevistas, tornando essa relação uma "conversação ordinária" (Mayer, 1995, pp. 359-360). Por fim, uma crítica é endereça- 
da à proposta de Bourdieu de uma mistura perigosa entre literatura e ciência, por meio de uma aproximação incauta da redação dos comentários das entrevistas a uma forma literária desabrida, especialmente nesse livro.

Apesar das críticas, o objetivo político do trabalho de Bourdieu foi de fato alcançado, seu livro fez carreira em todo o mundo e muita tinta correu em torno desse assunto. Ao mesmo tempo, tornou-se um livro de certa forma inclassificável na sua trajetória de pesquisador, pois rompeu de fato com várias diretrizes de seu próprio trabalho. Um livro a esquecer para os que clamavam por uma sociologia menos durkheimiana e menos cientificista que a de Bourdieu, um livro a criticar pelos que perceberam sua metodologia ameaçada por uma proposta polêmica e instigante.

Deveríamos assumir essa obra como uma metodologia de trabalho a ser desenvolvida, um programa futuro de pesquisas ou uma ideia específica de intervenção política ligada a um momento histórico?

Após a publicação de $A$ miséria do mundo, Bourdieu parece adotar novos objetos e começa a trabalhar com conceitos mais afastados da sociologia tradicional. Parece inegável uma mudança de rumos nos seus trabalhos a partir dessa publicação. Nas suas intervenções desse período, certo grau de intimismo e autoanálise vai num crescendo, passando por Science de la science et réflexivité (2001), cujo capítulo final se desdobra na obra Esquisse pour une auto-analyse (2004).

No prefácio de um livro dedicado a uma sociologia mais inovadora e mais arriscada teoricamente, que a princípio transgride o limiar de segurança tradicional do campo, aquele que separa a religião da ciência, Bourdieu postula algumas possibilidades instigantes (cf. Maître e Bourdieu, 1994). Nesse diálogo introdutório, Bourdieu comenta que "foi necessário chegar a minha idade, e que eu tivesse um pouco mais de 'audácia' social, para ser capaz de fazer essa transgressão" (Idem, p. XVIII). Para o Bourdieu de Le métier de sociologue (1968), uma afirmação como essa não deixa de ser instigante:

É preciso deixar vir o objeto. Todos nós conhecemos isso em certo momento, o desejo de "fazer ciência", de ser reconhecido pela comunidade científica, de escapar aos estigmas que pesam sobre a sociologia, e sobre seu estatuto científico etc. Existem muitas outras razões, especialmente pessoais; durante um período, houve certo número de assuntos que considerava indecentes porque, na verdade, eles me aturdiam (Idem, 1994). 
Essa proposta centrou-se na possibilidade de elaboração de uma "biografia coletiva”, já delineada por Bourdieu em outros trabalhos e que tomou uma forma politizada de valorização das trajetórias individuais no livro $A$ miséria do mundo. Resumindo a discussão que empreendi alhures (cf. Montagner, 2007), uma biografia coletiva buscaria "substituir a poeira das histórias individuais por famílias de trajetórias intrageracionais no seio do campo da produção cultural" (Bourdieu, 1996, p. 292). O objetivo do pesquisador seria compreender e obter:

[...] o domínio das condições de existência e dos mecanismos sociais cujos efeitos são exercidos sobre o conjunto da categoria da qual eles fazem parte (a dos estudantes, dos operários, dos magistrados etc.) e o domínio dos condicionamentos inseparavelmente psíquicos e sociais associados a sua posição e a sua trajetória particulares no espaço social (Bourdieu, 2003, p. 700).

A partir dessa capacidade empática, de cunho sociológico, a "imaginação sociológica” tão valorizada por Wright Mills (1969), estamos aptos ao "exercício espiritual" da entrevista, no qual poderíamos provocar uma "autoanálise" do entrevistado que seria a base de uma "construção realista", uma objetivação das trajetórias individuais dentro de um todo coletivo (cf. Bourdieu, 2003, pp. 699-706).

Essa proposta de Bourdieu que procurei clarificar e trazer à tona, se bem que dentro da mesma linha de valorização dos materiais vividos e das trajetórias individuais, difere da proposta de Howard Becker, de "mosaico científico", um aglomerado de quadros menores, específicos, localizados em torno de um mesmo assunto ou tema. $\mathrm{O}$ acúmulo desses conhecimentos parciais geraria um grande painel multicolorido: aqui a ideia é de uma colagem de elementos heterônimos, dessimétricos, no entanto com um resultado geral harmônico (cf. Becker, 1986). O conceito de mosaico é interessante como uma abstração refinada em ciências sociais do processo de formação do conhecimento sociológico. A palavra mosaico provém de uma transformação fonética de opus musivum, o trabalho de revestimento aplicado à decoração das paredes e dos arcos das grutas ou fontes dedicadas às musas, chamados em grego de mouseîon, templo das Musas. Com o tempo a palavra estendeu-se à técnica em si mesma. Em geral o mosaico é uma composição na qual há um motivo principal que faz sentido quando temos uma visão final do todo acabado, mesmo que os temas parciais possam ser visualizados de forma independente. $\mathrm{O}$ que o define é o próprio processo 
de construção que pressupõe a justaposição e a aglutinação de uma série de pequenos pedaços, pequenas pedras, de partes em geral não perfeitamente ajustadas: essa é a arte secreta do desenho, a arte de harmonizar partes irregulares em torno de um motivo ou de um construto específico.

Apesar de valorizar esse grande mosaico subjetivo das entrevistas, Bourdieu sempre manteve os olhos na possibilidade da ciência como portadora do universal, da razão objetiva como método de descoberta. Se a miséria é localizada, ao mesmo tempo ela é universal, "do mundo". Por isso, o objetivo explícito do livro é a universalidade. Assim justifica-se o investimento em um tratamento diferente das histórias recolhidas.

De início, Bourdieu e colaboradores transcreveram as entrevistas praticamente na íntegra, com pequenas alterações que visavam dar sentido ao texto ou aportar esclarecimentos necessários (cf. Bourdieu, 2003). A publicação dos textos é fato raro em análises biográficas e em geral o material colhido fica restrito à cozinha metodológica, ao fazer pretérito à interpretação. Essa prática abre a possibilidade de uma análise ou leitura diferente dos conteúdos registrados da entrevista, e maior margem de interpretação dos depoimentos. Dessarte, os relatos são resultados das entrevistas e o comentário acontece do ponto de vista dos entrevistadores, cuja expressão se encontra mesclada nas obras por meio de conhecimentos científicos e hipóteses teóricas.

Em seguida, seu método em $A$ miséria do mundo é desenhar um quadro harmonioso a partir de traços desiguais, um todo com um mesmo objetivo estético. Em $A$ miséria do mundo é inegável uma mudança de enfoque quanto ao material utilizado na análise, pois a ordem geral do livro é apresentar uma série de entrevistas sobre pessoas comuns, desconhecidas, quase anônimas, um conjunto de pessoas, de seres humanos que formam uma constelação de cogumelos, um vasto pontilhado de pequenos pixels, de ínfimos pontos no espaço social. Essa constelação invisível de seres humanos, que não valem o que pesam, condenada à insustentável leveza do ser, ao anonimato em uma sociedade condenada à mídia, ao desempenho público, é o ponto de partida do livro. Os investigadores do social tornam-se grandes artistas dos finos traços, dos pontilhados, dos esboços inacabados do mundo social. Esse conjunto forma um grande quadro impressionista. Nele, os elementos constituem um único coeso a fazer sentido se vistos e apreciados em conjunto; muitas vezes a própria apreciação impõe uma distância mínima entre o observador e a pintura. Esse conjunto pressupóe uma ideia ou conceito central que se dispersa em traços individualizados. Essa ideia cen- 
tral em $A$ miséria do mundo é que dirige a pintura dessa constelação invisível de sofrimentos dispersos e ubíquos, de mazelas tanto universais como minúsculas, tanto pungentes como caladas no pensamento individual, tão desabridas quanto inexprimíveis.

Esses inúmeros traços dispersos, indistintos em si mesmos, indicam uma direção, uma tendência geral, um sentido comum, mesmo sendo distintos e parciais; ainda mais, essas direçôes podem se sobrepor sucessiva e parcialmente; ou então se justapor e criar novas composições que representam o resultado dessas superposiçōes. Em muitos sentidos, $A$ miséria do mundo é realmente uma composição impressionista.

Histórias de vida e biografia coletiva

Nesse painel, o que os traços ou as pinceladas dos autores representam seriam as experiências vividas, captadas pelo artista no universo em movimento da vida cotidiana, os momentos significativos das vidas individuais, em suma, o material por excelência da análise sociológica, como afirmou Florian Znaniecki.

Diversas propostas surgiram nas últimas décadas, sobretudo a partir dos anos de 1970, com a intenção de valorizar esses materiais. Em geral, Bourdieu nelas condenou a ilusão biográfica de um relato ou de uma história de vida, aquela responsável por projetar sobre todo o caminho percorrido pelo sujeito, sobre seus atos, decisões e atitudes, uma teleologia e um sentido obtido por meio de sua situação presente, seja ela valorizada socialmente, seja fracassada em termos de valores sociais dominantes.

Daniel Bertaux propôs como enfoque os "relatos de práticas", uma mudança de olhar que pressupõe "não mais concentrá-lo sobre a vida como objeto único e da qual buscaríamos retirar o sentido; mas, ao contrário, direcionar o olhar para as relaçôes sociais e interpessoais, que do ponto de vista de cada ser humano o cercam e penetram” (Bertaux, 1976, p. 201).

A tentativa central é a valorização do mundo subjetivo e das histórias individuais. Mas a grande questão de método é o obstáculo da universalização dessas histórias de vida, a passagem do individual ao coletivo.

Quanto a essa passagem, Ferrarotti (1983, pp. 44-45) assinala as maneiras tradicionais de lidar com as informações obtidas, como o uso das biografias como material ilustrativo de um conhecimento prévio; ou, então, como estudo de casos e análises qualitativas ligadas e posteriores a dados 
quantitativos, estes sim responsáveis pelo estabelecimento de hipóteses entre as relações causais centrais.

No entanto, nenhuma proposta discutida até aqui resolve satisfatoriamente o problema. As histórias individuais em si mesmas trazem inúmeras possibilidades de análise, e sua representatividade é sempre um ponto de discussão.

Por isso, até hoje a proposta de Bourdieu de tratar os relatos das trajetórias individuais parece uma excelente solução ao dilema investigador e investigado, entrevistador e sujeito vivenciado pelo conteúdo subjetivo, sobretudo se considerarmos essas trajetórias dentro de uma biografia coletiva. Seu grande mérito como metodologia é a constatação e as facilidades proporcionadas no que diz respeito à sua aplicação e seus objetivos, por estar grandemente inserida em uma "teoria de médio alcance" poderosa nos moldes mertonianos (cf. Merton, 1967), chamada "construtivismo genético", "teoria da práxis" ou "praxiologia”.

Em vários sentidos, a biografia coletiva guarda grandes semelhanças com a maneira de tratar a análise dos relatos de vida apresentada por Ferrarotti, ao defender a ideia da biografia de grupo, o que ele define como a biografia de um "grupo primário". Esse autor aprofunda e refina vastamente esse tipo de análise, que vale, assim, uma pequena digressão em torno de seus argumentos.

Para ele, a história de vida como material primário essencial das ciências sociais é a base de uma aposta metodológica na capacidade inerente dessas histórias de vida de portarem invariantes estruturais, "convergências que emergem tematicamente nas histórias de vida singulares no interior de um horizonte histórico dado" (Ferrarotti, 1983, p. 31). Assim, a história faz do ser social um ser histórico, e por meio dela estamos todos unidos. Não uma história tradicional das elites, mas a famosa história "vinda de baixo", história que é "memória coletiva do cotidiano", do que é moeda corrente entre os grupos humanos concretos, pequenos, anônimos, efêmeros.

Se a práxis humana é o cerne dessa simbolização, da criação dos significados e dos sentidos das relações entre as pessoas, quando um indivíduo reconta sua história ele nos mostra uma fonte valiosa de conhecimento. Para Ferrarotti, "cada ato individual é a totalização de um sistema social, e uma vida é uma prática que se apropria das relações sociais (as estruturas sociais), as interioriza e as retransforma em estruturas psicológicas por sua atividade de desestruturação-reestruturação" (Ferrarotti, 1983, p. 50).

Esse movimento corresponde a uma mudança da história como disciplina, que introduziu progressivamente métodos e conceitos sociológicos 
em sua prática de pesquisa, e ao mesmo tempo uma mudança também da sociologia, que abandonou o macroestrutural e mirou as microrrelações humanas. De certo modo, cumpria-se a definição de Mills para a ciência social, destinada a estudar as relaçôes entre biografia e estruturas sociais dentro do processo histórico, e privilegiando a compreensão de uma psicologia individual, "sociologicamente fundamentada e historicamente relevante" (Mills, 1969, p. 156).

Em suma, a nossa questão aqui é aquela colocada brilhantemente por Sartre em seus trabalhos, sobretudo em Questão de método, sobre o problema metodológico que afligiu as ciências humanas nas últimas décadas, a saber, a análise das "mediaçôes sociais" que possibilitam explicar a passagem do todo ao particular, do macro ao micro, da parte à totalidade. Em nossa opinião, justamente a teoria bourdieusiana, com suas vicissitudes e virtudes, é a que melhor resolveu tais questões, estabelecendo coerentemente aquilo que Ferrarotti clama como necessário, uma "hierarquização das mediações":

O caminho heurístico que vai simultaneamente de uma biografia a uma sociedade e de uma sociedade a uma biografia implica por consequência uma teoria e uma tipologia das mediaçôes sociais que constituem os campos ativos das totalizaçôes recíprocas (Ferrarotti, 1983, p. 61).

A questão a ser resolvida é como transformar esse conhecimento cotidiano em artefato científico e, retomando nossa discussão, como generalizar a partir das experiências de entrevistas individuais. Os pressupostos básicos aqui assumidos consideram que cada entrevista e relato é uma interação complexa, cujo resultado sofre a interferência do campo social de comunicação (na teoria bourdieusiana isso significa uma possível "violência simbólica”), e a análise deve ser assumida como a hermenêutica de uma interação que reproduz todo o universo social.

No entanto, a teoria da práxis de Bourdieu opõe dificuldades práticas de análise, pois compreender um campo como um todo não é tarefa evidente a realizar.

A proposta de Ferrarotti inova ao "substancializar" uma instância intermediária entre o campo e o agente social, o grupo primário ou grupos locais, pois para ele "o grupo primário revela ser o momento fundamental de mediação entre o social e o individual" (Idem, p. 62). Por esse motivo, a escolha do grupo primário como centro dos interesses do método biográfi- 
co vem, de acordo com nossa proposta de análise e de construção, de uma biografia coletiva. Nos termos do autor:

Tomado como ponto de partida obrigatório, relacional e heurístico, o grupo permite eliminar a etapa mais complexa de todo método biográfico: a compreensão da totalização infinitamente rica que um indivíduo opera no seu contexto e exprime por meio das formas cifradas de um relato biográfico (Idem, p. 64).

A proposta é baseada na constatação de que as pessoas percebem o grupo a partir de sua perspectiva individual e se constroem como uma persona, mediante essa relação com o grupo:

Pelas desestruturaçōes e reestruturaçôes do contexto que ela opera, a prática do grupo é a mediadora e a reprodutora ativa da totalidade social nos seus microrregistros formais e informais, nas suas linhas de poder e de comunicação, normas e sançôes, modalidades, redes de interação afetiva etc.; o grupo em si mesmo tornase por sua vez - e simultaneamente - o objeto da prática de síntese de seus membros (Idem, p. 62).

Nessa linha de raciocínio, Luc Boltanski propõe a análise de um grupo a partir de seu próprio movimento histórico de constituição. De acordo com seu espaço social de atuação, suas regras implícitas e explícitas de funcionamento, seus códigos secretos e outros modos de diferenciação:

[...] nós podemos tentar analisar a forma do grupo interrogando o "trabalho de reagrupamento", de inclusão e exclusão, do qual ele mesmo é produto, analisando o "trabalho social de definição e delimitação" que acompanhou a formação do grupo e que contribuiu, objetivando-o, a criá-lo como um fato natural existente por si mesmo (Boltanski, 1981).

Pode-se afirmar que uma "persona coletiva” (personne collective) representa uma identidade social, uma marca de pertencimento, um conjunto flutuante, mas que simultaneamente mantém sua estabilidade e integridade no tempo. O conceito de Boltanski remete a uma dialética constante entre o grupo, que é essa identidade coletiva construída, e o indivíduo, que se define como pessoa, ao menos parcialmente, por ser um integrante desse grupo social. A coesão de um grupo flutuante, embora característico, de uma "persona coletiva", só pode ser mostrada de forma reflexiva: 
Nós não poderíamos assim construir hipóteses sobre a formação e as propriedades dos instrumentos cognitivos (esquemas, categorias, conceitos etc.), por meio dos quais os agentes pensam o grupo e seu pertencimento ao grupo sem relacioná-los com a estrutura do grupo e sua história, dos quais esses instrumentos são o produto interiorizado e reificado, e que eles reproduzem, por seu turno, cada vez que são colocados em prática (Idem, pp. 342-343).

Partindo da ideia de um grupo primário como portador de uma personalidade coletiva, podemos então considerar o conceito de illusio de Bourdieu como a interiorização pelo indivíduo dessa imagem grandemente socializada do grupo ao qual ele pertence e que toma a forma de uma "autoimagem social", imagem construída sobretudo por meio da posição social do grupo, illusio na qual se condensa tanto sua disposição pessoal como o poder social do cargo. Nesse ponto, imbrica-se o investimento disposicional de uma personalidade individual e o investimento institucional de uma personalidade coletiva, mediante o conceito de illusio. Se o indivíduo carrega para os postos ou cargos de poder seus desejos e projeçôes libidinais, ele é subsumido pelas instituições que em si mesmas, e por motivos necessários e suficientes ao seu funcionamento, o colocam nas malhas dos investimentos institucionais do poder.

$\mathrm{O}$ resultado gerado pela sobreposição desses investimentos gera uma illusio social diferente, uma mistura de um papel no sentido interacionista e de um habitus no sentido bourdieusiano, um amálgama que poderíamos chamar de "máscara social", como empregado por Mauss para designar a pessoa pública, jurídica, social, em suma, a "persona” (cf. Mauss, 2001, pp. 381-382).

Somos, ao mesmo tempo, face e máscara, pelo inegável de uma ligação profunda entre nossos desejos mais íntimos e nossos investimentos em um campo social, por meio da incorporação profunda da illusio do campo e das instituições do campo.

Como argumenta Claude Dubar, as maneiras pelas quais os sociólogos definem suas teorias de socialização ou, do parecido ao similar, suas teorias da ação dependem de como definem e distinguem a "identidade pessoal" e a "identificação social". Uma orientação ligada à psicologia, baseada na realidade inegável de um $e u$, uma realidade substancialista, permanente e autônoma, é definida por Dubar como essencialista. Uma outra, relativista, reduz o $e u$ e a identidade biográfica a uma ilusão que mascara a real posição do indivíduo no sistema das classes sociais, uma ilusão responsável pela 
negação de tudo o que o agente deve à sua posição social no campo (cf. Dubar, 1998).

A proposta então de realização de uma biografia coletiva por intermédio dos grupos primários nos remete à ideia de uma mediação entre uma identidade pessoal e social, entre o social e o individual, sobrepujando as posições "essencialistas" e "relativistas". Essa mediação evidencia as relações entre o autobiográfico e o histórico, entre o que pertence ao sujeito, ao eu, ao intimamente pessoal, e o que pertence ao social, ao coletivo, ao universal. Sem cairmos na velha armadilha de considerar como real a separação teórica dessas duas esferas, podemos retomar as relações entre as memórias individuais e as memórias coletivas, como propôs Maurice Halbwachs (1997).

Esse pensador foi o grande fundador dos estudos sobre memória em sociologia e inaugurou uma linha de pensamento sobre os modos de apreensão do mundo simbólico pelos indivíduos, aprofundando e inovando a proposta de Durkheim. A enorme tarefa a que se propôs foi compreender os mecanismos individuais e os coletivos de formação da memória e, ao mesmo tempo, estabelecer as diferenças sutis entre os dois tipos:

Deveríamos então distinguir de fato duas memórias, que chamaríamos, se desejarmos, uma de interior ou interna, outra de exterior; ou melhor uma memória pessoal, outra memória social. Nós diríamos mais precisamente ainda (a partir do ponto de vista que acabamos de indicar): memória autobiográfica e memória histórica. A primeira se apoiaria na segunda, pois a história de nossa vida faz parte da história em geral. Mas a segunda seria, naturalmente, muito mais extensa que a primeira. Por outro lado, ela só representaria o passado de uma forma resumida e esquemática, enquanto a memória de nossa vida nos apresentaria um quadro muito mais contínuo e denso (Idem, p. 99).

Compreender a relação entre a memória individual e a coletiva representa simultaneamente estudar e entender os mecanismos tanto da socialização como dos processos de formação de identidades, pois eles ocorrem simultaneamente e são as bases das permanências das regularidades estruturais da sociedade. Reescrevendo o mesmo raciocínio, podemos postular que qualquer teoria de ação passa, na sociologia contemporânea, pela compreensão das maneiras pelas quais o social é interiorizado nos recônditos e complexos mecanismos individuais, sem por isso entrarmos em uma sociologia de forte acento psicológico, mas em permanente aproximação a uma psicologia social. 
Para Halbwachs, a memória social, memória coletiva dos grupos sociais, desenha-se como um quadro surrealista, um conjunto que mescla as memórias individuais de inúmeros indivíduos, que estabelecem um resultado final que se reforça pelos pequenos pedaços, muitas vezes irreconhecíveis, dos fragmentos dispersos das lembranças pessoais. Primeiro o reconhecimento, o retraçar das mesmas linhas sobre os sulcos já velhos das lembranças. Em seguida, a alteração desses sulcos com a mescla de linhas parecidas, vindas de outras memórias individuais. Mais além, a sobreposição dessas lembranças pela preservação histórica assegurada pelas estruturas sociais, como necrológios, ritos, rituais, comemoraçōes históricas, existência física de dados cronológicos; tudo isso gera um quadro de memória coletivo, ou social, como o imaginado por Salvador Dalí, em 1931, para representar $A$ persistência da memória:

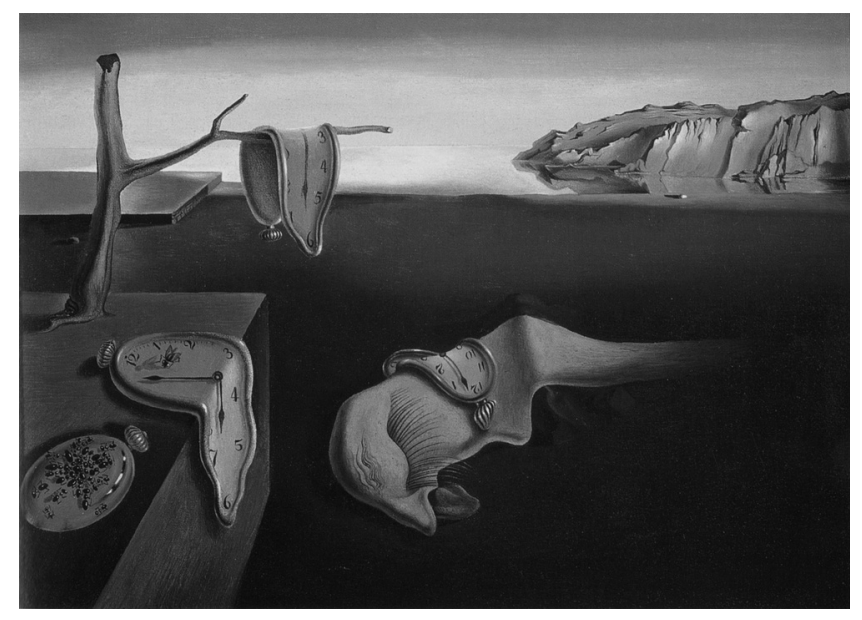

Já a memória individual, do tipo autobiográfico, é composta por todos os sinais e traços que guardamos, que alguma vez ouvimos, experimentamos, sentimos, olhamos, e que permanecem guardados e inativos. Esses fragmentos pertencem muitas vezes ao domínio dos sonhos, das lembranças da infância longínqua, das falas dos seres próximos e de um mundo de fantasmagorias. Poderíamos representar esse esmaecimento, de novo, pela célebre criação de Dalí de 1952-1954, chamada $A$ desintegração da persistência da memória. Nela, os traços transformam-se, recobrem-se, são justapostos, sedimentam-se em camadas superpostas e são refundidos em novas memórias, resultado de um trabalho de interpretação e reajustamentos no tempo: 


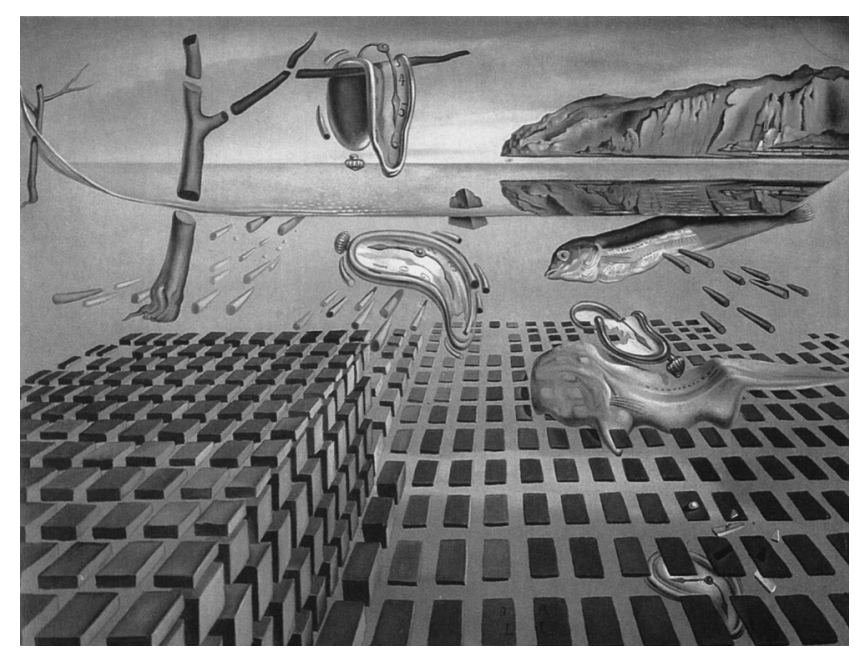

Assim, a relação entre as duas memórias é exemplificada por Halbwachs com suas lembranças familiares, sobretudo aquelas ligadas a seu pai. $\mathrm{O}$ encobrimento da memória pessoal autobiográfica pela memória histórica, social, é uma passagem capital na obra do autor, pois nos autoriza a tratar a memória como um objeto sociológico:

Tudo aquilo de novo que aprendo sobre meu pai, e também sobre aqueles que estiveram em relação com ele, todos os julgamentos novos que tenho sobre a época na qual ele viveu, todas as reflexões novas que faço, à medida que me torno mais capaz de refletir e que disponho de mais termos de comparação, me inclinam a retocar seu retrato. É assim que o passado, tal como me aparecia antigamente, se degrada lentamente. As novas imagens recobrem as antigas como nossos parentes mais próximos se interpõem entre nós e nossos ancestrais longínquos, de tal forma que destes nós conhecemos somente aquilo que aqueles relatam. Os grupos dos quais faço parte nas diversas épocas não são os mesmos. Ora, é a partir deles que considero o passado. Assim, é claro que à medida que me engajo mais nesses grupos e que participo mais estreitamente de suas memórias minhas lembranças se renovam e se completam (Idem, p. 123).

Por fim, analisar, nos grupos primários, as maneiras pelas quais as memórias se transformam, como elas são influenciadas pelos registros sociais e pela evolução histórica, parece ser o meio de excelência de obtermos uma valorização das experiências vividas dentro de uma perspectiva coletiva e por meio da memória do próprio grupo social. 


\section{Conclusão}

Se a prática científica realizada com o objetivo de atuar politicamente proposta por Bourdieu, com um declarado engajamento, arrisca pôr em xeque a prática científica em si mesma, ao introduzir uma temática ad hoc, então, como realizar uma prática científica ao mesmo tempo rigorosa e não conservadora, um método universal (ou que visa a esse estatuto) e uma intervenção consequente do ponto de vista social? Volta-se à tensão sempre presente entre uma prática intelectual dividida entre uma ética de convicção ou de responsabilidade, entre a escolha da ciência ou da política como beruf, nos termos weberianos.

Em diversos pontos, a concepção de Bourdieu de uma sociologia engajada, que respeitasse o discurso das pessoas invisíveis embora ubiquamente presentes, fez sua história e atingiu o objetivo de sensibilização dos leitores e a própria mídia, substituindo grande parte das análises complexas do mundo social por discursos dos próprios agentes. Sobretudo, considero A miséria do mundo uma inflexão exemplar na teoria do autor, que merece aprofundamento teórico e a busca de técnicas explícitas de operacionalização de sua proposta, elementos que faltaram nas justificativas metodológicas presentes no livro.

Talvez o caminho seja a procura de uma prática coerente, plena do que Gramsci chamava de "bom senso", correlativa de demandas e anseios sociais por clareza, compreensão e pelo desvelar da vida em sociedade, uma prática ditada pela exigência de responsabilidade intelectual. Propomos evitar a total ausência, senão de um engajamento clássico, ao menos de um compromisso ético mínimo e de uma ética de responsabilidade de nossa parte, intelectuais "específicos".

Acreditamos que a grande figura a representar esse papel e essa posição do intelectual seja aquela de Dante, do homem disposto a escarafunchar a condição humana em todas as suas vertentes. Nessa viagem, cuja maior parte é pessoal, ele se depara com a grandeza e a mesquinhez do homem. Sem se tornar cínico ou indiferente, assume a posição de velar para que outros não sigam o caminho da danação. Essa imagem profunda da Divina Comédia foi vazada na figura de um homem que permanece à entrada do Inferno, sentado e refletindo sobre os que entram ou estão a entrar pelo seu Portal. Por várias razões, as imagens do intelectual orgânico gramsciano, do intelectual específico em Foucault e do pensador engajado em Bourdieu encontram enormes paralelos com a escultura de Auguste Rodin, $O$ pensa- 
dor, um homem imerso nas questôes das misérias e degradações humanas com as quais demonstra uma profunda empatia.

Em nossa proposta, então, o objetivo seria trabalhar com conjuntos de trajetórias e traçar, assim, uma biografia coletiva de um grupo primário, utilizando, para descrever essa biografia, as memórias biográficas dos agentes sociais imersos nesses grupos. Essa biografia coletiva estabeleceria como central o desenho de uma persona coletiva, uma identidade característica de todo o grupo, capaz de traduzir essas trajetórias diversas em uma trajetória grupal e modelar resultado das interações e da estrutura social que a concebeu. Ainda, essa personalidade coletiva seria o "sujeito coletivo" de uma série de ações, escolhas, opções, disposições, atitudes e atos distribuídos no tempo e no espaço social, que foram ao mesmo tempo causa e consequência da constituição do grupo, da própria persona coletiva.

Como método, é necessário, pois, relacionar esse material biográfico histórias ou relatos de vida, obtidos por técnicas qualitativas - com a memória social, oficial, histórica, construindo-se assim uma memória coletiva final que seria a memória social do grupo e não a dos indivíduos. Por meio dessa mediação, respeitar as perspectivas humanas em jogo e, da mesma maneira, objetivar cientificamente os espaços sociais e seus conflitos presentes na biografia de uma persona coletiva.

\section{Referências Bibliográficas}

BECKER, Howard S. (1986), "Biographie et mosaïque scientifique”. Actes de la Rcherche en Sciences Sociales, v. 62-63 (L'Illusion Biographique), juin.

Bensaï̀, Daniel \& Corcuff, Philippe. (1998), "Le travail intellectuel au risque de l'engagement". Agone, v. 18-19 (Neutralité \& Engagement du Savoir), pp. 17-46. BERTAUX, Daniel. (1976), Histoires de vies ou récits de pratiques? Méthodologie de l'approche biographique en sociologie. Paris, CNRS - Centre d'Etude des Mouvements Sociaux. BolTANSKI, Luc. (1981), Biographie d’ une personne collective: les “cadres", 1936-1975. Paris (Doctorat-es-lettres), Université Paris VII.

Bourdieu, Pierre. (1986), "L'illusion biographique". Actes de la recherche en sciences sociales, v. 62-63 (L'Illusion Biographique), juin.

. (1996), As regras da arte: gênese e estrutura do campo literário. São Paulo, Cia. das Letras.

(2001), Science de la science et réflexivité: cours du Collège de France 20002001. Paris, Raisons d'Agir. . (2003), A miséria do mundo. São Paulo, Vozes. 
. (2004), Esquisse pour une auto-analyse. Paris, Raisons d'Agir.

Bourdieu, Pierre et al. (1968), Le métier de sociologue. Paris, Mouton.

Dubar, Claude. (1998), "Trajectoires sociales et formes identitaires: clarifications conceptuelles et méthodologiques". Sociétés Contemporaines, v. 29, pp. 73-85, jan.

Ferrarotti, Franco. (1983), Histoire et histoires de vie: la méthode biographique dans les sciences sociales. Paris, Meridiens.

Foucault, Michel. (1988), Microfisica do poder. Rio de Janeiro, Graal.

Gramsci, Antonio. (1978a), Concepção dialética da história. Rio de Janeiro, Civilização Brasileira.

. (1978b), Os intelectuais e a organização da cultura. Rio de Janeiro, Civilização Brasileira.

Halbwachs, Maurice. (1997), La mémoire collective. Paris, Albin Michel.

MAître, Jacques \& Bourdieu, Pierre. (1994), "Avant-propos dialogué". In: L'autobiographie d’ un paranö̈aque. Paris, Economica.

Mannheim, Karl. (1976), Ideologia e utopia. Rio de Janeiro, Zahar.

Mauss, Marcel. (2001), Ensaios de sociologia. São Paulo, Perspectiva.

MAYER, Nonna. (1995), "L'entretien selon Pierre Bourdieu: analyse critique de La misère du monde". Revue française de sociologie, 36 (2), avril-juin.

Merton, Robert King. (1967), On theoretical sociology: five essays, old and new. Nova York, Free Press.

Mills, Wright C. (1969), A imaginação sociológica. Rio de Janeiro, Zahar.

Montagner, Miguel. (2007), “Trajetórias e biografias: notas para uma análise bourdieusiana”. Sociologias, ano 9, n. 17, pp. 240-264, jan./jun.

OrTIZ, Renato. (1989), A moderna tradição brasileira. São Paulo, Brasiliense. (2002), Ciências sociais e o trabalho intelectual. São Paulo, Olho D'água.

Paugam, Serge. (2005), Les formes élémentaires de la pauvreté. Paris, PUF.

PINTO, Louis. (2006), Sociologie des débats, débats en sociologie. Paris, EHESS.

\section{Resumo}

Biografia coletiva, engajamento e memória: A miséria do mundo

Este trabalho procura relacionar a proposta de biografia coletiva de Pierre Bourdieu e suas possibilidades teóricas com a questão histórica do "engajamento" político dos cientistas, o que acaba por nos inserir no debate sobre o que é um intelectual, tema caro a muitos autores. Como exemplo polêmico, a forma elaborada desse engajamento por Pierre Bourdieu, em seu livro A miséria do mundo, é debatida neste artigo. Por fim, o interesse foi elaborar, à luz dessas ideias, uma proposta coerente de análise das trajetórias sociais e histórias de vida dos indivíduos inseridos em grupos comuns, assumin- 
do como bases o conceito de memória coletiva de Halbwachs e de persona coletiva de Boltanski.

Palavras-chave: Bourdieu; Halbwachs; Biografia coletiva; Memória coletiva; Gramsci; Persona coletiva.

\section{Abstract}

Collective biography, commitment and memory: The weight of the world

This text aims to relate Pierre Bourdieu's proposal of collective biography and its theoretical possibilities to the historical question of the political 'commitment' of scientists, which pitches us once again into the debate on what is an intellectual, a key topic for many authors. As a polemical example, the article discusses the form in which this commitment is elaborated by Pierre Bourdieu in his book The weight of the world. It then seeks to develop these ideas into a coherent proposal for analyzing the social trajectories and life histories of individuals inserted in social groups, taking as its lead Halbwachs's concept of collective memory and Boltanski's notion of collective persona.

Keywords: Bourdieu; Halbwachs; Collective biography; Collective memory; Gramsci; Collective persona. 